JAMP: Jurnal Adminitrasi dan Manajemen Pendidikan

Volume 5 Nomor 1 Maret 2022, Hal : 8 - 16

Tersedia Online di http://journal2.um.ac.id/index.php/jamp/

ISSN 2615-8574 (online)

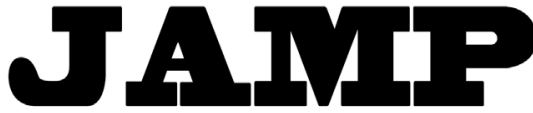

JURNAL ADMINISTRASI DAN MANAJEMEN PENDIDIKAN

\title{
MANAJEMEN PESERTA DIDIK BERBASIS IMTAQ PADA SEKOLAH DASAR
}

\author{
Farida, Farida Hanum, Abdul Rahim
}

\author{
Universitas Negeri Yogyakarta, \\ Jl. Colombo Yogyakarta No.1, Karang Malang, Caturtunggal, Kec. Depok, Kabupaten Sleman, \\ Daerah Istimewa Yogyakarta 55281 \\ E-mail: farida.2018@student.uny.ac.id. No. HP: 081215321046
}

\begin{abstract}
The purpose of this study is to describe the management of students with imtaq content at Al Azhar 31 Islamic Elementary School Yogyakarta. The type of research used is a case study. Data collection techniques in this study used interview techniques, observation techniques, and documentation techniques. The Miles and Huberman model used in this study was carried out through data collection, data reduction, data presentation, and verification or conclusion drawing. Check the validity of the data using triangulation. The subjects in this study were the principal, class teacher, Islamic religious education teacher, and imtaq builder. The results of the study show that the first pattern of student management is planning, the steps are needs analysis, recruitment, selection, orientation, placement, and student recording and reporting. Second, organizing, forming a student admissions committee with strategy and cooperation. The third implementation is carried out in four steps, namely coaching, learning, habituation, and evaluation. Fourth, supervision is carried out once in every semester by the principal and the $\mathrm{Al}$ Azhar foundation. The management steps of students containing imtaq aim to create a pious and noble person.
\end{abstract}

Keywords: Imtaq; Student management; Elementary school

\begin{abstract}
Abstrak: Tujuan dalam penelitian ini untuk mendeskripsikan manajemen peserta didik berbasis imtaq di Sekolah Dasar Islam Al Azhar 31 Yogyakarta. Jenis penelitian yang digunakan adalah studi kasus. Teknik pengumpulan data dalam penelitian ini menggunakan teknik wawancara, tenik observasi, dan teknik dokumentasi. Model Miles dan Huberman yang digunakan dalam penelitian ini dan dilakukan melalui pengumpulan data, reduksi data, penyajian data, dan verifikasi atau pengambilan kesimpulan. Pemeriksaan keabsahan data menggunakan triangulasi. Adapun yang menjadi subjek dalam penelitian ini adalah kepala sekolah, guru kelas, guru pendidikan agama islam, dan pembina imtaq. Hasil penelitian menunjukan bahwa pola manajemen peserta didik yang pertama adalah perencanan, langkahnya dengan analisis kebutuhan, rekrutmen, seleksi, orientasi, penempatan, serta pencatatan dan pelaporan peserta didik. Kedua pengorganisasian, pembentukan panitia penerimaan peserta didik dengan strategi dan kerjasama. Ketiga pelaksanaan, dilakukan dengan empat langkah yaitu pembinaan, pembelajaran, pembiasaan, dan evaluasi. Keempat pengawasan, dilaksanakan satu kali di setiap semester oleh kepala sekolah dan yayasan Al Azhar. Langkah-langkah manajemen peserta didik bermuatan imtaq bertujuan untuk menciptakan pribadi yang soleh dan berakhlak mulia.
\end{abstract}

Kata kunci: Imtaq; Manajemen peserta didik; Sekolah dasar

manajemen peserta didik merupakan suatu kegiatan yang meliputi beberapa langkah-langkah yaitu perencanaan, pengorganisasian, pelaksanaan serta kontrol (Farikhah 2015:3). Fungsi manajemen pendidikan (Kurniadin and Machali 2016:36) meliputi perencanaan, organisasi, pelaksanaan, dan pengawasan dimana sebuah organisasi yang baik harus menjalankan fungsi dalam manajemen. 
Manajemen peserta didik merupakan manajemen yang berupa pengelolaan peserta didik dari peserta didik dinyatakan diterima sampai dengan menjadi alumni (Eka Prihatin 2014:13; Nurjanah et al. 2019:255; Umam 2018:63). Manajemen peserta didik meliputi perencanaan peserta didik, pembinaan peserta didik, dan evaluasi peserta didik (Suwardi 2017:110). Manajemen peserta didik penting (Hamidah 2018:9; Kubat 2018:2; Rahmi 2014:2) karena sebagai tempat dimana peserta didik mengembangkan potensi yang dimilik (Bouchon, Hussain, and Konar 2015:3), baik yang berkenaan dengan segi individualitasnya, sosialnya, aspirasinya, kebutuhannya, dan potensi lain peserta didik, (Diantoro 2018:3; Imron 2016:12; Meng 2016:1).

Manajemen peserta didik yang baik akan memberikan dedikasi bagi pencapaian visi, misi dan tujuan dari sekolah tersebut (Rifa'i 2019:20; Rismita 2020:1), tercapaianya prestasi belajar yang baik (Sahney 2016:3; Firmanto 2018:5), dan memberikan keluaran alumni yang kompeten (Gage et al. 2017:3; Naidoo 2019:1). Peran kepala sekolah sangat dibutuhkan dalam suatu lembaga pendidikan (Wahyudin 2018:251). Kepala sekolah menjadi orang yang paling bertanggung jawab terhadap kemajuan sekolah (Alifiyah, Imron, and Juharyanto 2019:34; Ekosiswoyo 2016:76; Mahardhani 2015:1). Agar manajemen peserta didik berhasil dengan baik kepala sekolah harus menyusun serangkaian kegiatan yang berhubungan dengan manajemen peserta didik (Guangcai 2017:2; Mulyadi et al. 2019:16). Kurang pahamnya pendidik dengan perkembangan peserta didiknya akan menjadi hambatan dalam proses manajemen peserta didik (Akın, Yıldırım, and Lin Goodwin 2016:2; Huong, Tung, and Hanoi 2019:43; Mestry 2017:2; Nuswantari 2018:42) karena peserta didik merupakan bagian dari kualitas lembaga pendidikan (Gudmundsdottir et al. 2018:3; Suwardi 2017:97).

Peningkatan kualitas pendidikan, melatih, dan membekali pendidikan peserta didik dalam bentuk kegiatan salah satunya kegiatan keagamaan. (Syukri et al.2019:6). Pelaksanaan pendidikan agama mampu menghantarkan peserta didik yaitu keimanan, ibadah, dan akhlak (Gazali 2018:34; Iswati 2017:43). Imtaq dapat menumbuhkembangakan potensi peserta didik melalui manajemen peserta didik yang benar (Supriadi 2015:1). Karakter religius dan sosial siswa juga dikembangkan melalui pembelajaran dikelas dan pembentukan karakter melalui ektrakurikuler (Malla et al. 2020:299). Membina program imtaq bukan hanya tugas guru Pendidikan Agama Islam, tetapi tugas seluruh pendidik (Munawaroh 2018:21). Peran pemimpin sangat dibutuhkan untuk menciptakan lingkungan yang berwawasan iman dan takwa, oleh karena itu pengelola pendidikan juga harus menciptakan suasana organisasi untuk mencapai tujuan organisasi sekolah (Malla et al. 2020:299; Rismita 2020:5; Widiana and Timan 2019:233) dengan membentuk generasi yang beriman dan bertakwa kepada Alloh SWT.(Guangcai 2017:3; Puspitaningtyas et al. 2020:2).

Kurangnya pendidikan iman dan takwa menjadikan rendahnya sikap moral siswa seperti ucapan, tindakan yang tidak sopan dan menjadikan tidak adanya rasa hormat peserta didik kepada guru (Dewi et al. 2015:1), begitu pula dengan kenakalan remaja saat ini akibat pergaulan yang salah, seperti tawuran, pencurian, prostitusi maupun narkoba, sampai dengan kasus bulliying dan pendidikan imtaq juga belum dilaksakan oleh semua guru (Diantoro 2018:2; Hartini, Tryanasari, and Maruti 2016:29), Penanaman moral saat ini belum berhasil terbukti dari fatologi sosial pada remaja karena pembinaan iman dan takwa peserta didik di sekolah dianggap hanya kewajiban guru Pendidikan Agama Islam (Tang 2018:3). Melihat masalah tersebut di atas, perlu dikaji lebih lanjut mengenai manajemen peserta didik berlandaskan iman dan takwa.

SD Islam Al Azhar adalah salah sekolah unggulan di Yogyakarta yang menerapkan nilai imtaq dalam pengelolaan peserta didik. Sekolah ini memiliki ciri khas, yaitu memadukan kurikulum nasional yaitu K-13 dan kurikulum pengembangan pribadi muslim Al Azhar (KPPM). Penelitian ini penting dilakukan karena bertujuan untuk mendeskripsikan manajemen peserta didik yang dapat menambah wawasan pengetahuan pengelola sekolah tentang manajemen peserta didik berbasis imtaq untuk sekolah dasar yang bermanfaat untuk sekolah, guru, dan dinas pendidikan dalam mengelola lembaga. 


\section{METODE}

Penelitian ini menggunakan pendekatan kualitatif, jenis penelitian studi kasus yang memfokuskan sasaran pada manajemen peserta didik berbasis imtaq. Penelitian ini di SD Islam Al Azhar 31 Yogyakarta karena sekolah tersebut merupakan sekolah yang memiliki ciri khas dalam pengelolaan peserta didik dan menggunakan dua kurikulum. Informan sekunder penelitian ini kepala sekolah, guru kelas, guru pendidikan agama islam, pembina iman dan taqwa. Teknik pengumpulan data pada penelitian ini adalah wawancara, observasi dan studi dokumentasi yang berhubungan dengan subjek penelitian dan pertanyaan penelitian. Analisis data menggunakan langkah-langkah pengumpulann data, penyajian data, reduksi data, dan kesimpulan (Mathew B. Milles and A. Michael Huberman, 1994).

\section{HASIL DAN PEMBAHASAN}

Hasil temuan terwujud dalam pola manajemen peserta didik berbasis imtaq pada Sekolah Dasar pada gambar 1 .

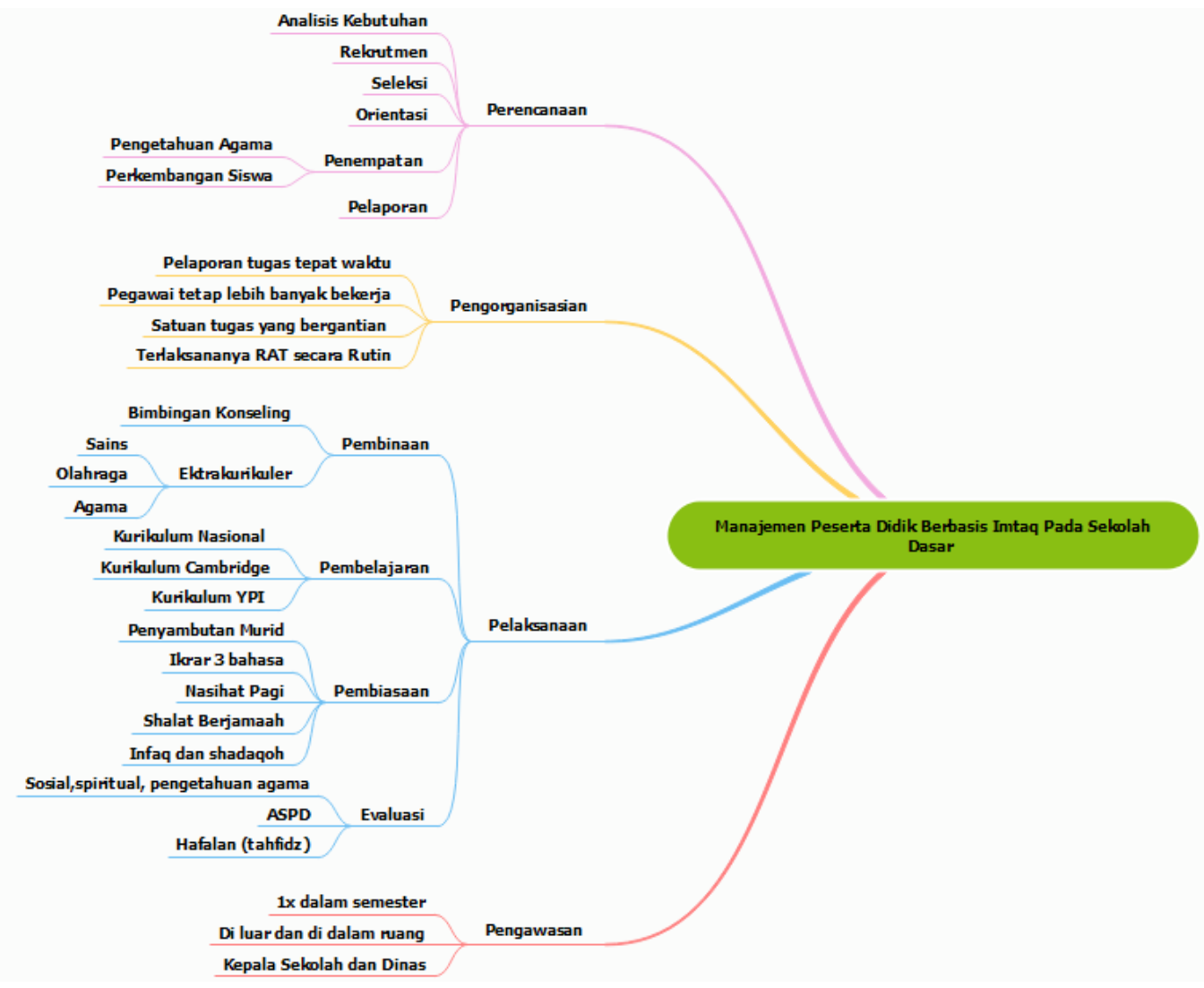

Gambar 1. Pola Manajemen Peserta Didik Berbasis Imtaq Pada Sekolah Dasar

\section{Perencanaan}

Kegiatan dalam perencanaan peserta didik yaitu analisis kebutuhan, rekrutmen, seleksi, orientasi, penempatan, pencatatan dan pelaporan peserta didik. Analisis kebutuhan peserta didik yaitu penempatan peserta didik yang dibutuhkan oleh lembaga pendidikan dan dilakukan ketika akan penerimaan peserta didik baru (Suwardi 2017:110). Dalam analisis peserta didik materi yang digunakan untuk observasi adalah pengamatan visual, pengamatan auditori, ingatan auditori, kemampuan bahasa, kemampuan berpikir, sosial emosional, motorik kasar, motorik halus, profil perkembangan kemampuan dasar dan pengetahuan agama. Tujuan dari observasi untuk pemetaan supaya guru mengetahui kemampuan calon peserta didik yang nantinya akan diterima.

Perencanaan peserta didik di SD Islam Al Azhar 31 Yogyakarta disusun mengikuti tujuan dan kebutuhan yang menginginkan peserta didiknya mempunyai perkembangan yang baik di sekolah. Proses 
perencanaan ini untuk menentukan calon peserta didik dengan ketersediaan kelas dan merencanakan kebutuhan guru sesuai dengan kebutuhan. Perencanaan adalah proses menjelaskan tujuan organisasi untuk mencapai hasil yang diinginkan (Gunawan and Benti 2017:37)

Langkah yang kedua yaitu rekrutmen peserta didik. Rekrutmen peserta didik adalah kegiatan mencari dan mendapatkan peserta didik yang dianggap layak untuk mengikuti proses pembelajaran dan telah melewati berbagai macam proses tes (Ubaidillah 2017:21). Rekrutmen calon peserta didik SD Islam AL Azhar 31 Yogyakarta dengan membuat brosur, melakukan pendekatan dengan masyarakat, mendatangi TK disekitar. Dengan strategi yang dilakukan supaya lingkungan sekolah mengetahui informasi mengenai penerimaan peserta didik. Adapun Syarat calon peserta didik yaitu berumur 6 tahun pada bulan Juli, memiliki Ijazah TK. Sedangkan untuk peserta didik pindahan dapat menambahkan surat keterangan pindah dari sekolah yang disahkan Kepala Dinas, surat keterangan berkelakukan baik, dan validasi NISN dari Dinas Pendidikan. Rekruitmen peserta didik dilakukan oleh kepala sekolah, guru, dan staf sebagai administrator dan dilaksanakan sebelum bulan Mei. Karena tujuan dari rekrutmen peserta didik untuk menetukan kriteria calon peserta didik yang sesuai dengan kebutuhan sekolah (Suwardi 2017:111).

Seleksi peserta didik dilakukan dengan cara: pertama, tahap seleksi awal berupa seleksi administrasi, hal ini merupakan kegiatan meneliti data calon peserta didik pada formulir pendaftaran sesuai persyaratan penerimaan dan dilaksanakan di SD Islam Al Azhar 31 Yogyakarta; kedua, seleksi akademik calon peserta didik di tes terkait dengan pengamatan visual, ingatan visual, pengamatan auditori, ingatan auditori, kemampuan bahasa, kemampuan berpikir, sosial emosional, motorik kasar, motorik halus, profil perkembangan kemampuan dasar dan pengetahuan agama; ketiga, tahap wawancara dengan cara pihak sekolah memanggil orang tua ke sekolah. Pada tahap ini ada komunikasi antara kepala sekolah dan orang tua siswa, yang di jelaskan oleh kepala sekolah yaitu Danar Kusuma "dalam proses seleksi ini pihak sekolah memanggil orang tua untuk tahap wawancara yaitu memberitahu persyaratan dari sekolah bahwa saat pelaporan hasil evaluasi peserta didik atau pengambilan rapor adalah orang tua dari peserta didik itu sendiri, bukan wali peserta didik. Seleksi peserta didik sesuai dengan hasil analisis observasi peserta didik yang sesuai dngan kualifikasi dan diakhiri dengan wawancara dengan orang tua siswa, dilihat dari kegiatan sleksi peserta didik bertujuan untuk menentukan diterima atau tidaknya calon peserta didik (Suwardi 2017:111) Jika persyaratan tersebut disetujui oleh orang tua peserta didik maka peserta didik dinyatakan diterima, selanjutnya ketahap penandatanganan dan yang terakhir adalah proses pembayaran.

Setelah Calon peserta didik diterima selanjutnya mengikuti kegiatan orientasi peserta didik. Orientasi peserta didik adalah perkenalan sekolah yang meliputi sarana prasarana sekolah, kepala sekolah, guru, tenaga pendidik dan kependidikan, teman sebaya, dan senior di sekolah (Imron 2016:73). Orientasi dilakukan di dalam dan di luar ruangan yang sudah ditentukan tim. Pelaksanaannya selama satu minggu pertama di kelas masing-masing dan pada tiga hari pertama didampingi orang tua. Orientasi peserta didik memberi pemahaman kepada peserta didik mengenai program sekolah, falisitas sekolah, tata tertib sekolah, dan macam-macam kegiatan yang ada di sekolah supaya peserta didik mengatahui tujuan sekolah. Kegiatan orientasi menjadikan peserta didik semangat, melatih kemampuan bersosialisasi di luar ruangan dan dapat menyalurkan bakat (Sururi 2009:210)

Selanjutnya siswa ditempatkan sesuai dengan hasil keputusan kepala sekolah. Penempatan peserta didik setiap tahun berubah sesuai dengan nilai raport. Sedangkan penempatan wali kelas berdasarkan hasil keputusan kepala sekolah. Pengelompokan peserta didik dan wali kelas dilaksanakan pada akhir tahun ajaran secara bersamaan. Penempatan peserta didik sesuai dengan kualifikasi yang telah diumumkan saat peserta didik dinyatakan diterima. Selanjutnya untuk kelas 2 sampai kelas 6 peserta didik dapat berpindah kelas untuk menghindari penumpukan siswa pintar dalam satu kelas. Penempatan peserta didik selalu berubah setiap tahunnya karena penempatan peserta didik merupakan sebuah upaya yang dilakukan untuk membuat klasifikasi kelas yang sesuai dengan tujuan (Ilyasin 2019:77). Tujuan diberlakukan perubahan kelas untuk menghindari adanya kelas ekslusive tetapi yang diharapkan adalah inklusive. Penempatan peserta didik berdasarkan perbedaan yang ada pada setiap individu. Selanjutnya peserta didik dapat mengikuti pembelajaran. 
Pencatatan data peserta didik diperoleh dari data peserta didik saat pendaftaran mulai dari ijazah, identitas peserta didik, riwayat keluarga dan prestasi peserta didik yang sangat membantu proses input data. Pencatatan kehadiran dan izin dari peserta didik tertera pada buku catatan peserta didik yang berupa buku absen dan buku harian. Pelaporan peserta didik dilaksanakan setiap semester dan dilakukan oleh guru dengan cara memasukan hasil rekap nilai para siswa kedalam laporan penilaian peserta didik. Pencatatan dan pelaporan bertujuan agar lembaga mampu melakukan bimbingan yang optimal pada peserta didik, sedangkan pelaporan sebagai bentuk tanggung jawab lembaga dalam perkembangan peserta didik (Shafira 2019:27).

\section{Pengorganisasian}

Pengorganisasian SD Islam Al Azhar 31 Yogyakarta khususnya pembentukan panitia penerimaan peserta didik baru, kepengurusan kemuridan, kurikulum, dan sarana prasarana. Pengorganisasian kegiatan imtaq juga berupa pembagian tugas dan tanggung jawab setiap panitia. Dalam hal ini panitia secara bergilir dalam melaksanakan tugasnya agar supaya semua panitia memiliki pengalaman yang sama dalam tugasnya. Pengorganisasian adalah fungsi kedua dalam manajemen dan sebagai proses kegiatan penyusunan struktur organisasi sesuai dengan tujuan, sumber, serta lingkungan (Maisaro, Wiyono, and Arifin 2018:304).

Pengorganisasian SD Islam Al Azhar 31 Yogyakarta dilanjutkan dengan pembagian tugas dan tanggung jawab kepada pengurus. Pembagian tugas dengan cara musyawarah antara semua koordinator dan guru-guru. Kepala sekolah melaksanakan tugas manajerial, wakil kepala sekolah membantu tenggung jawab kepala sekolah, BK memberikan layanan dan pelaporan kegiatan, koordinator kemuridan mengemban tugas kesiswaan, koordinator kurikulum menyusun program pengajaran, koordinator keagamaan mengatur kegiatan yang berkesinambungan dengan keagamaan yang ada si sekolah, tata usaha mengarsipkan surat menyurat dan administrasi sekolah koordinator ektrakurikuler, koordinator sapras mengecek dan menpersiapkan kebutuhan pembelajaran, dan guru bidang mengajar siswa di dalam maupun luar ruang kelas. Organisasi adalah kumpulan orang yang saling bekerjasama untuk mecapai tujuan tertentu (Janan Asifudin 2016:359).

\section{Pelaksanaan}

Pelaksaaan manajemen peserta didik di SD Islam Al Azhar 31 melalui berbagai kegiatan yaitu proses pembinaan, pembelajaran, pembiasaan, dan evaluasi. Proses pembinaan peserta didik dapat dilakukan melalui beberapa kegiatan. Semua peserta didik memperoleh bimbingan konseling (BK) dan terdapat siswa yang mengikuti program Pembinaan Anak Berbakat (PAB) melalui kegiatan ektrakurikuler yang ada di sekolah seperti budaya jawa, menari, berkuda, basket, pencak silat science club, english club, melukis, robotika, jurnalis cilik,murota dan marawis. Kegiatan PAB dilaksanakan setelah jam pembelajaran selesai yaitu pukul 14.00 sampai dengan selesai. Kegiatan ektrakurikuler dilaksanakan diluar jam pembelajaran guna untuk memperluas wawasan dan nilai pengetahuan dan kemampuan pada berbagai bidang (Hanafi, Ulfatin, and Zulkarnain 2020:52). Pembinaan peserta didik adalah kegiatan yang berhubungan dengan manajemen peserta didik yang dilakukan oleh sekolah(Diantoro 2018:17)

Kegiatan pembelajaran SD Islam Al azhar 31 Yogyakarta dimulai pukul 07.15 sampai dengan 12.00. Kurikulum yang digunakan yaitu kurikulum nasional yaitu Kurikulum 13 (K-13) dan Kurikulum Pengembangan Pribadi Muslim Al Azhar (KPPM). Kegiatan pembelajaran disekolah selalu mengaitkan Hadist dan Al-qur'an dengan tema pembelajaran yang akan disampaikan sudah dicantumkan di dalam RPP dan silabus.

Proses pembiasaan yang dilaksakan di SD Islam Al Azhar 31 Yogyakarta terdiri dari kegiatan menyambut murid dengan 3S (Senyum, Salam, Sapa), ikrar, do'a, tadarus Al-Qur'an, nasihat pagi, shalat berjama'ah, infaq dan shadaqah. Ciri khas SD Islam Al Azhar 31 dipagi hari sebelum kegiatan pembelajaran dimulai melafalkan ikrar terlebih dahulu. Lafal ikrar sebagi berikut "Bismillaahirrohmaanir-rohiim Asyhadu al-laa ilaaha illallooh Wa asyhadu anna Muhammadar-rosuulullooh Rodhiitu billaahi robbaa Wa bil Islaami diinaa Wa bi Muhammadin-nabiyyaaw-warosuulaa Wa bil quraani imaamaw-wahakamaa Robbii zidnii 'ilmaa Warzuqnii fahmaa Aamiin. Alloohummaghfir lii, wa 
liwaalidayya, warham humaa, kamaa robbayaanii shoghiiroo" ikrar dilafalkan dengan tiga bahasa yaitu dengan bahasa indonesia, bahasa inggris, dan bahasa arab, selanjutnya melaksankan program literasi, dan diakhiri dengn membaca alqur'an. Do'a dilaksanakan dengan khusyu' dan kerendahan hati untuk memperoleh keberkahan dan ridha dari Alloh SWT. Kegiatan do'a dilaksanakan di semua kegiatan, minimal didahului dengan istighfar, basmalah, tahmid, shalawat, dan ditutup dengan bacaan hamdalah. Cara berdoa dengan mengangkat kedua tangan sejajar bahu, posisi duduk atau berdiri. Tadarus AlQur'an dilakukan oleh murid, dan guru menyimak serta memperhatikan adab murid terhadap AlQur'an serta memperbaiki bacaan murid yang belum benar. Nasihat pagi dilaksanakan 3 menit setelah tadarus Al-Qur'an dan disampaikan oleh guru dengan pesan yang memotivasi belajar yang dikutip dari hadis. Pembiasaan shalat berjamaah di sekolah. Sekolah menjadwalkan petugas kegiatan shalat berjamaah. Sekolah menugaskan guru dalam pendampingan shalat berjamaah, melakukan evaluasi pencapaian program pembiasaan shalat berjamah secara berkala, dalam satu sekolah dapat mengadakan shalat berjamaah secara bersamaan. SD Islam Al Azhar 31 Yogyakarta memiliki program infaq dan sadaqah. Program sekolah berupa santunan untuk anak asuh serta beasiswa untuk anak anak asuh yang berkelanjutan. Pelaksanaan kegiatan infaq dan shadaqah dengan cara membuat laporan keuangan kepada pimpinan sekolah.

Selanjutnya proses evaluasi untuk menentukan prestasi belajar peserta didik dengan menggunakan patokan-patokan tertentu guna mencapai tujuan pembelajaran yang telah ditentukan (Imron 2016:119). Penilaian peserta didik yang dilakukan oleh sekolah berpatokan dengan beberapa catatan diantaranya: dilihat dari kompetensi inti yakni spiritual, kepribadian, pengetahuan dan ketrampilan berdasarkan harian, tengah semester dan akhir semester. Adapun ketentuan dalam penilaian, jika nilai mata pelajaran agama dibawah KKM, maka peserta didik dinyatakan tidak lulus, dan jika tiga mata pelajaran selain agama dibawah KKM juga dinyatakan tidak lulus. Seperti yang tercantum di KI dan KD kurikulm 2013 di SD 31 menilai siswa dari kompetensi inti mencakup empat dimensi yang mencerminkan sikap spiritual, sikap sosial, pengetahuan, dan keterampilan. Keempat dimensi tersebut dirancang sebagai pengintegrasi muatan pembelajaran, mata pelajaran, atau program dalam mencapai Standar Kompetensi Lulusan. Pelaksanaan menjadikan perencanaan menjadi kegiatan yang dilalui dengan berbagai arahan dan motivasi sesuai dengan tugas dan tanggung jawab (Marhawati 2018:7). Dari penilaian yang sudah ditetapkan di atas digunakan untuk evaluasi, agar supaya guru dapat mengetahui kemampuan siswa dalam memahami materi yang disampaikan kepada peserta didik, evaluasi dilaksanakan bertujuan untuk melihat kemajuan belajar peserta didik dalam penguasaan materi yang telah dipelajarinya serta sebabsebab kemajuan dan kegagalan belajar guna untuk memperbaiki mutu pelajaran dan metode mengajar (Rifa'i 2019:177).

\section{Pengawasan}

Pengawasan yang dilakukan oleh SD Islam Al Azhar 31 Yogyakarta dua kali dalam satu semester, evaluasi dilakukan untuk meningkatkan kualitas pendidik dengan penilaian yang telah ditetapkan. Selain penilaian oleh kepala sekolah penilaian juga dilakukan oleh pengawas yayasan Al Azhar. Dengan adanya penilaian di SD Islam Al Azhar 31 Yogyakarta mejadikan semangat guru meningkat, karena pengawasan adalah kegiatan untuk mengukur operasional dan hasil harus dicapai dengan patokan yang telah ditetapkan dalam perencanaan (Kurniadin and Machali 2016:131) dan Pengawasan sangat penting untuk menentukan baik buruknya suatu rencana, maka harus dilakukan dengan sebaik-baiknya (Maisaro et al. 2018:304).

\section{SIMPULAN DAN SARAN}

\section{Simpulan}

Kesimpulan dari penelitian ini yaitu: (1) perencanaan, kegiatan perencanaan meliputi analisis kebutuhan peserta didik sesuai dengan kebutuhan, rekrutmen peserta didik dengan cara pembuatan brosur, pendekatan dengan masyarakat, dan kunjungan, seleksi peserta didik dengan pengamatan visual auditori kemampuan bahasa, sosial emosional serta kemampuan agama, orientasi peserta didik dilakukan 
dengan cara pengenalan aktifitas disekolah, organisasi, fasilitas, tenaga pendidik dan kependidikan serta tata tertib sekolah, pencatatan dan pelaporan peserta didik menggunakan buku identitas peserta didik, buku harian siswa, dan absen, pelaporan menggunakan buku raport.; (2) pengorganisasian, dilakukan dengan cara pembentukan panitia penerimaan peserta didik, Bimbingan Konseling siswa, koordinasi kemuridan, koordinasi kurikulum, koordinasi sarana dan prasarana, dan koordinasi imtaq berupa pembagian tugas serta tanggung jawab setiap panitia.; (3) pelaksanaan dilakukan melalui empat proses yaitu pembinaan, pembelajaran, dan evaluasi. Pembinaan peserta didik dengan bimbingan konseling serta ekrakurikuler di sekolah, pembelajaran di SD Islam Al Azhar 31 menggunakan kurikulum nasional yaitu k-13 dan Kurikulum Pengembangan Pribadi Muslim Al Azhar (KPPM). Proses pembiasaan dilakukan dengan ikrar tiga bahasa yaitu bahasa arab, bahasa Indonesia dan bahasa Inggris yang dilakukan sebelum kegiatan pembelajaran, adapun kegiatan tadarus Al-Qur'an, nasihat di pagi hari, shalat berjama' ah, serta kegiatan infaq dan shadaqah karena SD Islam Al Azhar 31 Yogyakarta memiliki program santunan beasiswa anak asuh; dan (4) pengawasan dilakukan oleh kepala sekolah dan yayasan Al Azhar, kegiatan pengawasan dilaksanakan dua kali dalam satu semester untuk meningkatkan kualitas pendidik dengan penilaian yang ditetapkan untuk mengukur kegiatan operasional yang sudah ditetapkan didalam perencanaan.

\section{Saran}

Saran yang diberikan dalam penelitian ini kepada peneliti lain, hasil yang telah didapat oleh peneliti bisa dijadikan untuk sumber referensi bagi peneliti yang akan melakukan dengan tema yang sama dan bisa dijadikan referensi untuk mendeskripsikan manajemen peserta didik disekolah lain. Peneliti juga menyarankan untuk meneruskan penelitian ini sesuai dengan perkembangan zaman dimana semua proses manajemennya menggunakan digitalisasi, sehingga dapat menemukan hasil yang berbeda dan bermanfaat untuk peneliti berikutnya.

\section{DAFTAR RUJUKAN}

Akın, Sibel, Ali Yıldırım, and A. Lin Goodwin. 2016. "Classroom Management through the Eyes of Elementary Teachers in Turkey: A Phenomenological Study." Kuram ve Uygulamada Egitim Bilimleri 16(3):771-97. doi: 10.12738/estp.2016.3.0376.

Alifiyah, Ika, Ali Imron, and Juharyanto Juharyanto. 2019. "Kepemimpinan Visioner Kepala Sekolah Dalam Mengembangkan Karakter Peserta Didik." Jurnal Administrasi Dan Manajemen Pendidikan 2(1):032-039. doi: $10.17977 / \mathrm{um} 027 \mathrm{v} 2 \mathrm{i} 22019 \mathrm{p} 32$.

Bouchon, Frederic, Kashif Hussain, and Rupam Konar. 2015. "Event Management Education and Event Industry: A Case of Malaysia." MOJEM: Malaysian Online Journal of Educational Management 3(1):1-17.

Darma, Hamidah. 2018. "Manajemen Peseta Didik." Jurnal Serunai Administrasi Pendidikan 6(2):1-10. doi: 10.37755/jsap.v6i2.35.

Dewi, Fatikah Rahma, Nurul Azmi, and Ria Yulia Gloria. 2015. "Penerapan Pembelajaran Biologi Berbasis IMTAQ Pada Konsep Ekosistem Untuk Meningkatkan Hasil Belajar Siswa Di Kelas X SMA Negeri 1 Jamblang.” Scientiae Educatia: Jurnal Pendidikan Sains 5(2). doi: 10.24235/sc.educatia.v4i2.489.

Diantoro, Fery. 2018. "Manajemen Peserta Didik Dalam Pembinaan Perilaku Keberagamaan." Cendekia: Jurnal Kependidikan Dan Kemasyarakatan 16(2):409. doi: 10.21154/cendekia.v16i2.1207.

Dutta, Vartika, and Sangeeta Sahney. 2016. "School Leadership and Its Impact on Student Achievement: The Mediating Role of School Climate and Teacher Job Satisfaction." International Journal of Educational Management 30(6):941-58. doi: 10.1108/IJEM-12-2014-0170.

Ekosiswoyo, Rasdi. 2016. "Kepemimpinan Kepala Sekolah Yang Efektif Kunci Pencapaian Kualitas Pendidikan." Jurnal Ilmu Pendidikan 14(2):76-82.

Farikhah. 2015. Lembaga Pendidikan 2015. I. Yogyakarta: Aswaja Pressindo.

Firmanto, Rian Anugrah. 2018. "Pengaruh Manajemen Pembelajaran Terhadap Kinerja Guru Dalam Mewujudkan Prestasi Belajar Siswa." Jurnal Pendidikan UNIGA 12(1):1-11.

Gage, Nicholas A., and Ashley S. MacSuga-Gage. 2017. "Salient Classroom Management Skills: Finding the Most Effective Skills to Increase Student Engagement and Decrease Disruptions.” Report on Emotional \& Behavioral Disorders in Youth 17(1):13-18. 
Gazali, Syukeri. 2018. "Pendidikan Anak Dalam Keluarga Perspektif Islam.” Jurnal Ilmiah Darul Ulum 9(1):75106.

Guangcai. 2017. "On the Application of Blended Learning in College English Teaching." (Icem):555-58. doi: 10.2991/emim-17.2017.91.

Gudmundsdottir, Greta Björk, and Ove Edvard Hatlevik. 2018. "Newly Qualified Teachers' Professional Digital Competence: Implications for Teacher Education.” European Journal of Teacher Education 41(2):214-31. doi: 10.1080/02619768.2017.1416085.

Gunawan, and Benti. 2017. Manajemen Pendidikan Suatu Pengantar Praktik. Bandung: Alfabeta.

Hanafi, Ahmat, Nurul Ulfatin, and Wildan Zulkarnain. 2020. "Manajemen Kegiatan Ekstrakurikuler Broadcasting Dalam Meningkatkan Kreativitas Peserta Didik.” Jurnal Administrasi Dan Manajemen Pendidikan 3(1):5260. doi: 10.17977/um027v3i12020p52.

Hartini, Hartini, Dewi Tryanasari, and Endang Sri Maruti. 2016. "Pendidikan Karakter Siswa Sekolah Dasar Melalui Pembelajaran Seni Budaya." Premiere Educandum : Jurnal Pendidikan Dasar Dan Pembelajaran 5(01):128-39. doi: 10.25273/pe.v5i01.329.

Huong, Vu Thi Mai, Nguyen Thi Thanh Tung, and Hanoi. 2019. "Perspectives of Lecturers and Students on Classroom Management in Vietnam Universities." Malaysian Online Journal of Education Management 7(3):43-63.

Ilyasin, Mukhamad. 2019. "Manajemen Peserta Didik Dalam Mengaktualisasikan Nilai-Nilai Karakter Di Satuan Pendidikan." Fenomena 11(1):69-79. doi: 10.21093/fj.v11i1.2143.

Imron, Ali. 2016. Manajemen Peserta Didik Berbasis Sekolah. Jakarta: Bumi Aksara.

Iswati. 2017. "Transformasi Pendidikan Agama Islam Dalam Membangun Nilai Karakter Peserta Didik Yang Humanis Religius." Sangyo Igaku 9(5):557.

Jaja Jahari dan Amirulloh Syarbini. 2013. Manajemen Madrasah. Bandung: PT Alfabet.

Janan Asifudin, Ahmad. 2016. "Manajemen Pendidikan Untuk Pondok Pesantren." MANAGERIA: Jurnal Manajemen Pendidikan Islam 1(2):355-66. doi: 10.14421/manageria.2016.12-10.

Kubat, Ulas, and Nurhak Cem Dedebali. 2018. "Opinions of Science Teachers for Classroom Management." Journal of Education and E-Learning Research 5(2):110-17. doi: 10.20448/journal.509.2018.52.110.117.

Kurniadin, Didin, and Imam Machali. 2016. Manajemen Pendidikan Konsep \& Prinsip Pengelolaan Pendidikan. Yogyakarta: Ar-Ruzz Media.

Mahardhani, Ardhana Januar (Universitas Muhammadiyah Ponorogo). 2015. “Kepemimpinan Ideal Kepala Sekolah." Jurnal Dimensi Pendidikan Dan Pembelajaran 3(2):1-4.

Maisaro, Atik, Bambang Budi Wiyono, and Imron Arifin. 2018. "Manajemen Program Penguatan Pendidikan Karakter Di Sekolah Dasar.” Jurnal Administrasi Dan Manajemen Pendidikan 1(3):302-12. doi: 10.17977/ um027v1i32018p302.

Malla, Hamlan Andi Baso, Khaeruddin Yusuf, M. Tahir Sapsuha, and Misnah Misnah. 2020. “The Transformative Leadership of School Principal Paradigm in Developing Students' Religious and Social Characters." Al-Ta Lim Journal 26(3):298-308. doi: 10.15548/jt.v26i3.581.

Marhawati, Besse. 2018. Pengantar Pengawas Pendidikan. Yogyakarta: CV.Budi Utama.

Meng, Liangqiu. 2016. "College Student Management System Design Using Computer Aided System." Proceedings - 2015 International Conference on Intelligent Transportation, Big Data and Smart City, ICITBS 2015 212-15. doi: 10.1109/ICITBS.2015.59.

Mestry, Raj. 2017. "Empowering Principals to Lead and Manage Public Schools Effectively in the 21st Century." South African Journal of Education 37(1):1-11. doi: 10.15700/saje.v37n1a1334.

Mulyadi, Didi, Subaiki Ikhwan, Ahmad Gawdy Prananosa, Rusi Rusmiati Aliyyah, and Widyasari Widyasari. 2019. "Manajemen Kesiswaan Pada Sekolah Dasar." DIDAKTIKA TAUHIDI: Jurnal Pendidikan Guru Sekolah Dasar 6(1):29. doi: 10.30997/dt.v6i1.1355.

Munawaroh, Faezatul. 2018. "Program Magister Ilmu Agama Islam Universitas Islam Indonesia Program Magister Ilmu Agama Islam Universitas Islam Indonesia.” 1-98.

Naidoo, Parvathy. 2019. "Perceptions of Teachers and School Management Teams of the Leadership Roles of Public School Principals.” South African Journal of Education 39(2):1-14. doi: 10.15700/saje.v39n2a1534.

Nurjanah, Asti Faticha, Nur Karimah, and Aghita Wahyuningsih. 2019. "Manajemen Peserta Didik Di Smk Muhammadiyah 2 Yogyakarta." Al-Idarah: Jurnal Kependidikan Islam 9(2). doi: 10.24042/alidarah. v9i2.5192. 
Nuswantari, Nusi. 2018. "Model Pembelajaran Nilai-Nilai Toleransi Untuk Anak Sekolah Dasar." Premiere Educandum : Jurnal Pendidikan Dasar Dan Pembelajaran 8(1):41. doi: 10.25273/pe.v8i1.2255.

Prihatin, Eka. 2014. Manajemen Peserta Didik. Bandung: Alfabeta.

Puspitaningtyas, Indah, Ali Imron, and Maisyaroh Maisyaroh. 2020. “Upaya Kepala Sekolah Dalam Meningkatan Pembelajaran Guru Di Era Revolusi Industri 4.0.” Jurnal Manajemen Dan Supervisi Pendidikan 4(3):16572. doi: 10.17977/um025v4i32020p165.

Rahmi, Nurul. 2014. "Persepsi Guru Tentang Manajemen Peserta Didik SDN Gugus II Kec. Lubuk Sikarah Kota Solok." Jurnal Administrasi Pendidikan, Bahana Manajemen Pendidikan 2(1):528-34.

Rifa'i, Muhammad. 2019. Manajemen Peserta Didik. Vol. 3. Medan: CV.Widya Puspita.

Rismita, Rismita. 2020. "The Management Of The Education Operational Grant And Its Effects On School Development.” JPI (Jurnal Pendidikan Indonesia) 9(2):328. doi: 10.23887/jpi-undiksha.v9i2.21218.

Shafira, U. 2019. "Strategi Kepala Sekolah Dasar Dalam Rekrutmen Siswa Baru Di SDN 20 Banda Aceh."

Supriadi. 2015. "Kegiatan Ekstrakuler PAI Dalam Mengembangkan Wawasan Kegamaan Peserta Didik Di SMP Darul Fallaah Unismuh Bissoloro Kecamatan Bungaya Kabupaten Gowa.” Tesis Pascasarjana UIN Alauddin Makasar.

Sururi dan S Nasihin. 2009. Manajemen Peserta Didik. Dalam Manajemen Pendidikan. Tim Dosen Administrasi Pendidikan Universitas Pendidikan Indonesia. Bandung: Alfabeta.

Suwardi. 2017. Manajemen Peserta Didik. Edisi Ke-1. Malang: Gava Media, Yogyakarta.

Syukri, Icep Irham Fauzan, Soni Samsu Rizal, and M. Djaswidi Al Hamdani. 2019. "Pengaruh Kegiatan Keagamaan Terhadap Kualitas Pendidikan.” Jurnal Penelitian Pendidikan Islam 7(1):17. doi: 10.36667/jppi.v7i1.358.

Tang, Muhammad. 2018. "Pengembangan Strategi Pembelajaran Pendidikan Agama Islam (PAI) Dalam Merespon Era Digital.” Fikrotuna 7(1):717-40. doi: 10.32806/jf.v7i1.3173.

Ubaidillah, A. 2017. "Rekrutmen Peserta Didik Dalam Meningkatkan Mutu Lembaga Pendidikan.” Etheses.UinMalang.Ac.Id.

Umam, M. Khoirul. 2018. "Meningkatkan Mutu Pendidikan Melalui Manajemen Peserta Didik." FALASIFA : Jurnal Studi Keislaman 9(2):1-20. doi: 10.36835/falasifa.v9i2.115.

Wahyudin, Wahyudin. 2018. "Optimalisasi Peran Kepala Sekolah Dalam Implementasi Kurikulum 2013.” Jurnal Kependidikan 6(2):249-65. doi: 10.24090/jk.v6i2.1932.

Widiana, Riski Ariska, and Agus Timan. 2019. "Manajemen Malam Bina Iman Dan Taqwa Untuk Penguatan Karakter Peserta Didik." Jurnal Administrasi Dan Manajemen Pendidikan 2(4):222-31. doi: 10.17977/ um027v2i42019p222. 